\title{
Prolonged peripheral anosmia in the rat by multiple intranasal applications of zinc sulfate solution
}

\author{
DONALD H. THOR, ROBERT W. CARTY, and KEVIN J. FLANNELLY \\ Edward R. Johnstone Training and Research Center, Bordentown, New Jersey 08505
}

\begin{abstract}
Forty rats trained to locate small pellets of cheese by olfactory cues were given one, two, or three intranasal applications of a zinc sulfate solution or placebo by intubation. Three applications of zinc sulfate at 3-h intervals rendered a higher percentage of rats anosmic for a longer duration than either one or two applications. A control group that received three applications of saline continued to locate cheese with efficiency comparable to pretest baseline. Advantages of intubation delivery through the nares include a simplified administration procedure and a decrease in potential debilitation or death due to inspiration of excess zinc sulfate solution.
\end{abstract}

Experimental olfactory deficit or anosmia may be induced by surgical ablation of the olfactory bulbs or by intranasal application of zinc sulfate (Alberts \& Galef, 1971). Alberts and Friedman (1972), however, have indicated that "anosmic" and "bulbectomized" may no longer be considered as synonomous. "Centrally induced anosmia" is obtained by olfactory bulbectomy, whereas "peripherally induced anosmia" is accomplished by intranasal application of zinc sulfate or anesthetics (Latané, Joy, Meltzer, \& Lubell, 1972). The effectiveness of zinc sulfate is thought to be caused by coagulation necrosis of the olfactory epithelium and is of temporary duration, with recovery of olfactory acuity within several days following treatment. Peripheral anosmia may well become the more common procedure for the simple reason that bulbectomy is known to produce disturbances in behavior not related to anosmia per se (Alberts, 1974).

The purpose of the present report is to provide evidence in support of a new variation in the Alberts and Galef (1971) technique for more reliable incidence and longer duration of anosmia by the zinc sulfate method. Multiple applications have been employed by Alberts and Friedman (1972) at 5-day intervals to provide sustained anosmia over a 2 -week test period, but the interspersion of repeated treatment applications among test sessions may be inappropriate in some investigations. Intranasal application of zinc sulfate solution through the nares of mice has been used by Edwards. Thompson, and Burge (1972) with $63 \%$ of animals anosmic on the day following treatment. Lisk. Zeiss, and Ciaccio (1972) perfused the nasal cavities of hamsters with $1.7 \%$ zinc sulfate solution. Mating was inhibited in five of six treated animals, but all recovered completely within $140 \mathrm{~h}$. Barnett, Cowan, Radford, and Prakash (1975) have recently reported $95 \%$ initial anosmia and $75 \%$ anosmia after 3 days in laboratory rats using the original Alberts and Galef (1971) method. Alberts (Note 1) has indicated a 5-day average for anosmia induced by zinc sulfate using the original method and a single application.

Stimulation for improvement in technique was prompted by high death rates in attempts to use the hooked catheter method of application (Ghiselli \& Thor, 1975). The original treatment procedure requires insertion of the hooked metal catheter (20-ga. syringe needle) into the throat and entering the esophagus, rotation, and retraction to enter the posterior nasal cavity. With the anesthetized animal in a supine position, the zinc sulfate solution is injected until eight drops are expelled from the external nares. Excess zinc sulfate solution and saliva are intermittently aspirated. After considerable practice with several dozen animals, debilitation and occasional deaths were still encountered and the conclusion was reached that, even with careful aspiration, some zinc sulfate solution was being inspired into the lungs (or alternatively, the experimenters were hopelessly inadequate as lab technicians).

Preliminary testing with polypropylene tubing indicated that a $2-\mathrm{cm}$ insertion into the nares is readily accomplished and that a small volume of zinc sulfate solution may be deposited at the ethmoturbinals without the requirement for flushing the entire nasal cavity from the posterior choanae. It was assumed that multiple applications of a relatively small volume may be at least equally and possibly more efficacious than a single flushing as originally described. Avoiding the use of a rigid metal cateheter was also considered as decreasing the potential for trauma to soft tissues of the throat.

Hence the present experiment sought to compare groups of trained cheese-locating rats on ability to locate cheese following one, two. or three applications 
of zinc sulfate solution. A salire-treated control group was included for purpose of providing a baseline for standard performance and to exclude any variables that may have been associated with repeated anesthesia or intubations.

\section{METHOD}

\begin{abstract}
Animals
Forty mature male Sprague-Dawley, Wistar, and Long-Evans rats were used. The Long-Evans rats were laboratory reared and the remaining strains were retired breeders from a commercial source (West Jersey Biological Farm. Wenonah, New Jersey). Each animal was individually housed in standard wire-mesh hanging cages. Random assignment to three experimental groups and one baseline control group was made with the constraint that each group be homogeneous with regard to strain composition.
\end{abstract}

\section{Procedure}

All rats were placed on a 23-h food deprivation cycle and trained to locate randomly buried pieces of sharp cheddar cheese. Each animal received five trials per day prior to normal feeding time until able to locate. dig up, and begin eating within a mean criterion of $<50 \mathrm{sec}$ per trial for five successive trials. The test box was an opaque plastic group cage $(41 \times 51 \times 22 \mathrm{~cm})$ filled to a $5-\mathrm{cm}$ depth with a commercial litter (Sani-cel, regular grade, Vivarium Research. Inc.) composed of ground corn cobs. Cheese particles were freshly cut cubes approximately $1 / 2, \mathrm{cc}$ in size. Following each daily test, each subject received $15 \mathrm{~g}$ of Purina Lab Chow pellets in its home cage. Cheese test screening and subsequent testing for anosmia after zinc sulfate treatment was conducted in two sequential runs with several extra animals on the second run to replace any losses due to failure to reach criterion on the screening task or death following treatment.

Preliminary to each zinc sulfate or placebo application, the animal was placed in an ether jar until vibrissal movement ceased. Upon removal, the animal was placed in a supine position. All treatments were administered sequentially on an individual basis at the same time of day during the normally dark segment of a reversed 12:12 light/dark cycle.

A . 2 - $\mathrm{ml}$ volume of $7.65 \%$ zinc sulfate solution (isotonic) or placebo solution (sodium chloride injection bacteriostatic, U.S.P., Abbott Laboratories) was slowly applied by syringe through an inserted polypropylene tube (Size PE 20, Clay-Adams, Inc.) attached by a plastic tubing adapter (No. A-1026, Size A. Clay-Adams. Inc.) to a $1-\mathrm{ml}$ syringe. Length of tubing was $12 \mathrm{~cm}$ from the adapter, but only $2 \mathrm{~cm}$ of the tip was inserted into the nares. $A$ rotating movement of the tube by the thumb and index finger facilitated insertion to a premarked indicator point on the tube, made with indelible ink. A precautionary aspiration of the posterior throat area was conducted simultaneously with injection of the zinc sulfate or placebo solution. Upon completion of the intranasal injection, and tube withdrawal, the animal was held downward with tip of nose held lightly against an absorbent towel. An extimated volume of $.1 \mathrm{ml}$ was drained from the nares in this manner during recovery from the ether, thus only $.1 \mathrm{ml}$ (approximately two drops) of the zinc sulfate solution was retained within the animal. Terminal placement of the inserted tube is located at base of ethmoturbinals as illustrated in Figure 1.

Following the zinc sulfate or placebo treatments, all animals received their daily food rations. Cheese testing resumed on the following day and each day thereafter for 10 consecutive days. An animal locating a randomly placed cheese pellet within $5 \mathrm{~min}$ on each of two successive trials was no longer considered anosmic and received five additional timed cheese tests on that day and each successive day thereafter.

Group 3 received a total of three intranasal injections of zinc sulfate solution $(.2 \mathrm{ml}$ each) with a $3-\mathrm{h}$ interval between each injection. Group 2 received two zinc sulfate injections of $.2 \mathrm{ml}$ each with a 3-h interval between each injection, and Group 1 received one intranasal zine sulfate application of $.2 \mathrm{ml}$. Group 0 received three applications of $.2 \mathrm{ml}$ placebo solution at $3-\mathrm{h}$ intervals. Treatment-group designation was random.

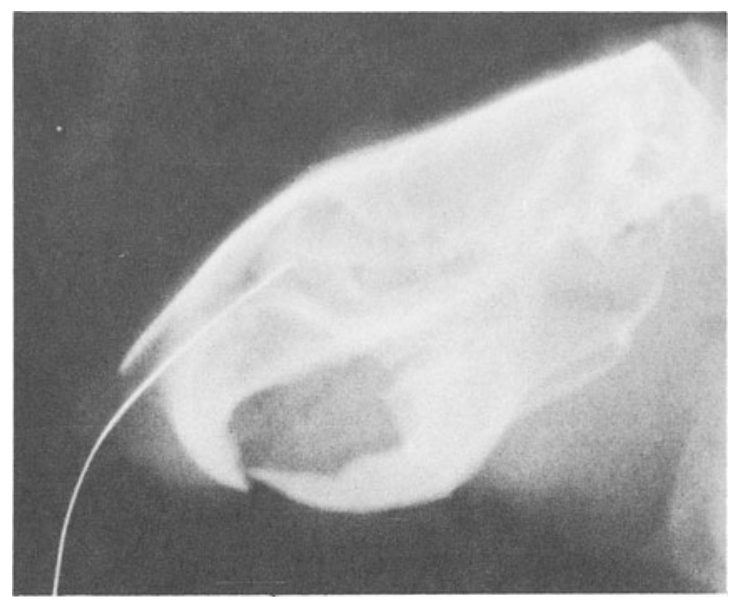

Figure 1. Lateral view of head showing 2-cm insertion of polypropylene tube. A thin copper wire was inserted into the tube after normal placement to render locus visible on x-ray film.

\section{RESULTS}

One animal in each of Groups 3 and 2 died approximately $24 \mathrm{~h}$ after receiving the zinc sulfate injections and were replaced. Three animals failing to locate cheese cubes within the mean criterion time (i.e., $<50 \mathrm{sec}$ ) on preliminary training were also replaced. Differences among pretest group mean latencies on the day prior to treatment were nonsignificant.

Mean cheese location time in seconds for each group ( $n=10$ /group) over 10 days is presented in Figure 2. A two-way ANOVA (treatments by days) with latency data following treatment indicated a significant treatment effect $[F(3,36)=40.41, p<.001]$, a significant effect over days $[F(9,324)=15.47, p<.001]$, and a significant interaction of treatment by days $[F(27,324)=3.88, p<.001]$. Dunnett's test for comparison of treatment means with a control mean

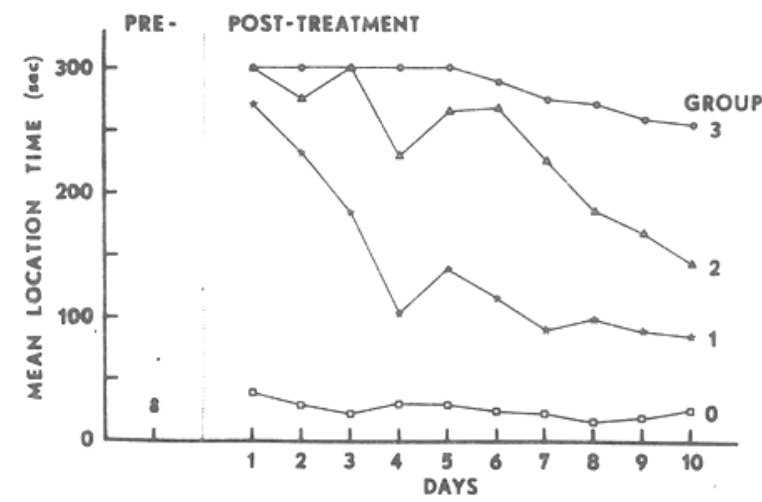

Figure 2. Mean time to locate cheese before and after zinc sulfate or placebo treatment. Group 3 received three $\mathrm{ZnSO}_{4}$ applications. Group 2 received two applications, and Group 1 recelved one application. Group 0 received three applications of sterile saline as baseline control. 
Table 1

Percentage of Animals Failing Cheese Location Test by Group Over Days Following Treatment*

\begin{tabular}{crrrrrrrrrr}
\hline & \multicolumn{10}{c}{ Day } \\
\cline { 2 - 10 } Group & 1 & \multicolumn{1}{c}{2} & \multicolumn{1}{c}{3} & \multicolumn{1}{c}{4} & \multicolumn{1}{c}{5} & 6 & 7 & 8 & 9 & 10 \\
\hline 3 & 100 & 100 & 100 & 100 & 100 & 90 & 80 & 80 & 80 & 80 \\
2 & 100 & 90 & 100 & 70 & 80 & 80 & 60 & 40 & 40 & 30 \\
1 & 80 & 70 & 50 & 20 & 30 & 30 & 20 & 20 & 20 & 20 \\
0 & 0 & 0 & 0 & 0 & 0 & 0 & 0 & 0 & 0 & 0 \\
\hline
\end{tabular}

*Failing to locate cheese on each of two discrete 5-min tests (original criterion) or five successive 5-min daily tests having once passed the original criterion.

was applied to the latency data for each day (Winer, 1962 , p. 89). Group 1 failed to differ significantly ( $>.05$ ) from the controls on Days $4,7,8,9$, and 10 . Groups 2 and 3 differed significantly from controls $(p<.01)$ on each of the 10 days. Percentage of animals failing to locate cheese during each day following treatment is indicated in Table 1.

At the conclusion of testing, all animals appeared in good health; experimental subjects did not visibly appear to differ from controls except in ability to locate the buried cheese. No significant strain differences were noted in reaching criterion of performance prior to treatment or in duration of anosmia following treatment.

\section{DISCUSSION}

The results demonstrate a distinct anosmic effect in all treated groups as compared with saline-treated controls. Apparently, the relatively small volume of isotonic zinc sulfate solution used is effective in blocking the ability of trained animals to locate buried cheese by olfactory cues. Considering the difference in volumes and concentrations of zinc sulfate solution used by varying investigators (the range appears to vary from several milliliters to $.001 \mathrm{ml}$; see Edwards et al.. 1972, p. 825), the single application of $.2 \mathrm{ml}$ administered to Group 1 in the present study appears as effective as the original perfusion method described by Alberts and Galef (1971) and recently applied by Barnett et al. (1975). Perhaps the critical element of multiple application is a prolonged duration of mucosal exposure to zinc sulfate solution. This interpretation would suggest that additional applications. perhaps as many as 8 or 10 at $2-\mathrm{h}$ intervals, would be even more effective in prolongation of the subsequent duration of anosmia.

In some experimental designs, duration of anosmia induced by peripheral zinc sulfate application is a determining variable, and the present data demonstrates that multiple applications are more effective than a single application in contributing to an extended duration of anosmia. Multiple applications (with intervals of several hours) of zinc sulfate solution by the original method would likely lead to unacceptable losses due to death or debilitation in the hands of many investigators.
Informal observation also indicates that in comparison with a previous application of the original technique in this laboratory (Ghiselli \& Thor, 1975), the general method of intranasal delivery herein described is more easily accomplished and entails decreased potential for trauma. The operator injects a smaller volume, in a specified quantity, and in closer proximity to the target area. Thus potential respiratory complications are diminished. The volume injected appears to be a critical variable since $.3 \mathrm{ml}$ was found to be considerably more lethal than $.2 \mathrm{ml}$ on preliminary testing; a $70 \%$ death rate was incurred with three injections of an .3-ml dosage of the zinc sulfate solution. When $.2 \mathrm{ml}$ is used and the animal is immediately held head downward to allow for drainage, aspiration of the throat during injection may not be necessary. A further suggested practice is to intubate both of the nares since the median cartilage (septum) may deflect the solution to one side of the dorsal nasal cavity.

In summary, $.2 \mathrm{ml}$ of zinc sulfate solution administered intranasally in each of several applications by intubation is more effective in reliably producing anosmia in rats. Duration of anosmia appears related to number of applications, and potential for injury or death is diminished by the use of a nonrigid applicator easily inserted via the external nares. Decreased volume of zinc sulfate solution required appears to diminish complications due to inspiration.

\section{REFERENCE NOTES}

1. Alberts, J. R. Personal communication, 1974.

\section{REFERENCES}

Alberts, J. R. Producing and interpreting experimental olfactory deficits. Physiology and Behavior, 1974, 12, 657-670.

Alberts, J. R., \& Friedman, M. I. Olfactory bulbe removal but not anosmia increases emotionality and mouse killing. Nature, 1972, 238, 454-455.

Alberts, J. R., \& Galef, B. G., JR. Acute anosmia in the rat: A behavioral test of a peripherally induced olfactory deficit. Physiology and Behavior, 1971, 6, 619-621.

Barnett, S. A., Cowan, P. E., Prakash, I., \& Radford, G. G. Peripheral anosmia and the discrimination of poisoned food by Rattus rattus L. Behavioral Biology, 1975, 13, 183-190.

EDWARDs, D. A., ThOMPson, M. L., \& BURGE, K. G. Olfactory bulb removal vs. peripherally induced anosmia: Differential effects on the aggressive behavior of male mice. Behavioral Biology, 1972, 7, 823-828.

GHiselLI, W. B., \& THOR, D. H. Visual, tactual, and olfactory deprivation effects on irritable fighting behavior of male hooded rats. Physiological Psychology, 1975, 3, 47-50.

Latané, B., Joy, V., Meltzer, J., \& Lubell, B. Stimulus determinants of social attraction in rats. Journal of Comparative and Physiological Psychology, 1972, 79, 13-21.

Lisk, R. D., Zeiss, J., \& Ciaccio, L. A. The influence of olfaction on sexual behavior in the male golden hamster (Mesocricetus auratus). Journal of Experimental Zoology, 1972, 181, 69-78.

WINER, B. J. Statistical principles in experimental design. New York: McGraw-Hill, 1962.

(Received for publication September 29, 1975.) 